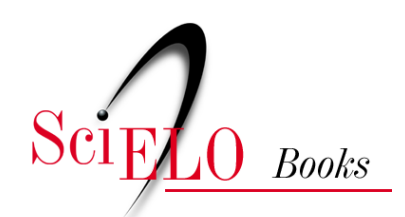

\title{
O aumento da população humana (colonização e crescimento vegetativo) e os impactos sobre a floresta com araucária - séculos XIX e XX
}

\author{
Miguel Mundstock Xavier de Carvalho
}

\section{SciELO Books / SciELO Livros / SciELO Libros}

CARVALHO, M.M.X. O aumento da população humana (colonização e crescimento vegetativo) e os impactos sobre a floresta com araucária - séculos XIX e XX. In: GERHARDT, M., NODARI, E.S., and MORETTO, S.P., eds. História ambiental e migrações: diálogos [online]. São Leopoldo: Oikos; editora UFFS, 2017, pp. 139-156. ISBN: 978-85-64905-68-9.

https://doi.org/10.7476/9788564905689.0010.



All the contents of this work, except where otherwise noted, is licensed under a Creative Commons Attribution 4.0 International license.

Todo o conteúdo deste trabalho, exceto quando houver ressalva, é publicado sob a licença Creative Commons Atribição $\underline{4.0}$.

Todo el contenido de esta obra, excepto donde se indique lo contrario, está bajo licencia de la licencia $\underline{\text { Creative Commons }}$ Reconocimento 4.0. 


\title{
$\mathrm{O}$ aumento da população humana (colonização e crescimento vegetativo) e os impactos sobre a floresta com araucária - séculos XIX e XX
}

\author{
Miguel Mundstock Xavier de Carvalho
}

\section{Introdução}

A dinâmica do desmatamento global acompanha de perto o crescimento demográfico, uma vez que a explosão populacional do último século está diretamente relacionada com o aumento da oferta de alimentos e, portanto, da expansão dos rebanhos e dos campos cultivados em detrimento das florestas. ${ }^{1}$ Como afirmou John McNeill, "o aumento secular da população humana nos últimos 250 anos é um dos mais curiosos e consequentes elementos da história moderna, bem mais importante do que a maioria dos historiadores reconhecem" (2006, p. 184). O crescimento populacional humano ao longo do século XX também está fortemente relacionado com o aumento do consumo de lenha, uma vez que o gás de cozinha (um recurso não renovável que no entanto ajudou a poupar as florestas nesse sentido) só se tornou comum na região da floresta com araucária na década de 1970 em diante. Além disso, o fato de o Brasil ser um país muito pobre em carvão mineral significou uma baixa utilização industrial de carvão ou mesmo de outros combustíveis fósseis, uma vez que a abundância de florestas por muito tempo significou lenha acessível e barata

\footnotetext{
${ }^{1} \mathrm{O}$ crescimento populacional no século XX é um processo disseminado no mundo todo e abrange as mais variadas culturas e sociedades. Acompanha de perto o aumento da produção de alimentos. A diminuição ou estabilização da população em geral só existe quando há guerras, conflitos, epidemias, catástrofes climáticas ou com a disseminação do uso de métodos contraceptivos nas sociedades urbanizadas. A relação entre agropecuária e crescimento populacional em sociedades agrárias pode ser considerada um processo retroalimentador, pois os agricultores se beneficiavam de famílias numerosas para o aumento da mão de obra, ao mesmo tempo em que a família numerosa exigia uma área de cultivo cada vez maior para sustentar a todos com as calorias adequadas.
} 
(BRANNSTROM, 2012). A seguir é feita uma análise do papel do aumento demográfico e seu impacto sobre o ecossistema floresta com araucária.

\section{Agropecuária, lenha e desmatamento}

Para uma avaliação geral do papel da agropecuária e do uso da lenha no desmatamento da floresta com araucária, elaborou-se uma tabela sobre o aumento da população humana na região da floresta com araucária de 1872 a 1960 (Tabela 1). A simples confecção dessa tabela demandou um considerável trabalho de coleta de dados dispersos e também a consulta de mapas e bibliografia especializada para que se pudesse chegar a um resultado o mais confiável possível.

O pressuposto básico é o de que o aumento da população humana na região da araucária, seja pelo crescimento vegetativo seja devido ao fluxo migratório, teve um impacto de grande alcance na floresta com araucária, como foi o caso em qualquer lugar do mundo, especialmente a partir da Revolução Industrial. De acordo com Michael Williams:

Desde 1700 a população do mundo tem mostrado uma tendência ao aumento praticamente irredutível, e o aumento nos números tem tido um impacto severo nas florestas do mundo. O total global era de 769 milhões em 1750, e dentro de 100 anos tinha praticamente dobrado para 1.260 milhões, para dobrar novamente para alcançar 2.515 milhões em 1950. A relação entre o número total de pessoas em um dado território e o desmatamento tem sido mostrada repetidamente como sendo positiva; é talvez uma força de que nós podemos estar absolutamente certos a respeito. O incremento de $270 \mathrm{mi}$ lhões de pessoas em 150 anos e sua inevitável dispersão significou a necessidade por mais terra para cultivar comida, mais madeira para prover abrigo e mais lenha para cozinhar e para o aquecimento. Os sistemas de pousio foram encurtados e intensificados, e em outros lugares a floresta foi derrubada para dar vez as plantações intensivas ou aos cultivos comerciais dos camponeses. O peso dos números populacionais pairou e ainda paira pesadamente sobre a floresta $(2006$, p. 235$){ }^{2}$

Além do crescimento vegetativo da população, favorecido pela alta taxa de natalidade e pela diminuição da mortalidade, a região da araucária foi afetada pela externalidade do excepcional crescimento da população

\footnotetext{
${ }^{2}$ Quanto à menção ao incremento de 270 milhões, parece ser um engano de Williams, pois esse número fica fora de contexto nesse parágrafo. De qualquer maneira, o argumento do autor não fica prejudicado.
} 
europeia nos séculos XVIII e XIX. Assim, ao menos 52 milhões de pessoas deixaram a Europa e a Rússia entre 1840 e 1930, a maioria para a América do Norte, mas também para a América Latina e Oceania (WILLIAMS, 2006, p. 237). Leo Waibel estimou para o ano de 1934 que a população de origem europeia nos três estados do sul do Brasil era de 1.643 .000 (1949, p. 180). ${ }^{3}$

A seguir temos o Gráfico 1, relativo ao crescimento populacional dos três estados do sul do Brasil, entre 1872 e 1970, período em que ocorreu uma intensa exploração madeireira e colonizadora, o que acarretou no quase total desaparecimento das florestas primárias com araucária.

Gráfico 1: Evolução histórica da população dos três estados do sul do Brasil (1872 a 1970)

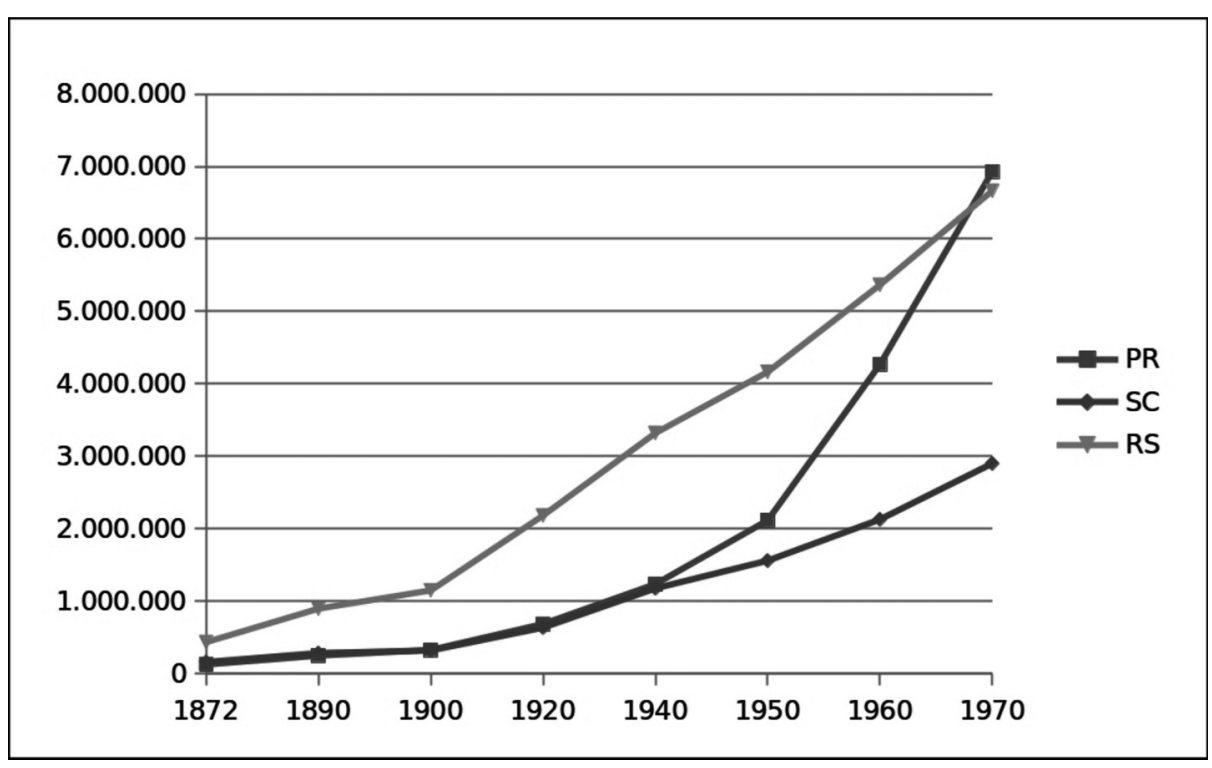

Fontes: RECENSEAMENTO, [S.I.: s.n.]. BRASIL, 1898; BRASIL, 1905; BRASIL,1928; BRASIL, 1950; BRASIL, 1955; BRASIL, 1960; BRASIL, 1970

No entanto, para uma análise mais refinada sobre o impacto da população humana sobre a floresta com araucária, elaborou-se a Tabela 1

\footnotetext{
${ }^{3}$ É preciso lembrar que Waibel estimou a população de origem europeia, e não simplesmente o número de imigrantes europeus que o sul do Brasil recebeu, pois nesse número estão incluídas pessoas descendentes de imigrantes, mas nascidas no Brasil.
} 
sobre a população da região da araucária, calculando apenas a população dos municípios que se localizam (ou que se localizam principalmente) na região da araucária, ou seja, no planalto sul-brasileiro. Para os detalhes dos dados, ver o Apêndice ao final do capítulo.

Tabela 1: População humana na região da araucária e estimativa do consumo anual de lenha somente para cozinhar (em toneladas) (1872-1960)

\begin{tabular}{|l|c|c|c|c|c|}
\hline \multicolumn{6}{|c|}{ População humana da região da araucária (a) } \\
\hline & Paraná & $\begin{array}{c}\text { Santa } \\
\text { Catarina }\end{array}$ & $\begin{array}{c}\text { Rio Grande } \\
\text { do Sul }\end{array}$ & Total & $\begin{array}{c}\text { Consumo anual } \\
\text { de lenha somente } \\
\text { para cozinhar } \\
\text { (em toneladas) (b) }\end{array}$ \\
\hline 1872 & 100.047 & 12.785 & 69.312 & 182.144 & 437.145 \\
\hline 1890 & 207.529 & 38.738 & 169.838 & 416.105 & 998.652 \\
\hline 1900 & 278.226 & 46.958 & 220.586 & 545.770 & 1.309 .848 \\
\hline 1920 & 567.731 & 167.135 & 521.661 & 1.256 .527 & 3.015 .664 \\
\hline 1940 & 871.762 & 431.387 & 871.389 & 2.174 .165 & 5.217 .996 \\
\hline 1950 & 1.156 .087 & 518.419 & 1.047 .809 & 2.722 .315 & 6.533 .556 \\
\hline 1960 & 1.966 .097 & 703.480 & 1.255 .627 & 3.925 .204 & 9.420 .489 \\
\hline
\end{tabular}

(a) - Calcula-se a população humana da região da araucária somando a população de todos os municípios localizados (ou principalmente localizados) na área original da floresta com araucária. Para uma discussão da metodologia e das limitações desses cálculos, ver o Apêndice.

(b) - O dado do consumo de lenha foi baseado na estimativa de Aníbal P. de Souza de que o consumo anual per capita de lenha para cozinhar era de $6 \mathrm{~m}^{3} .1 \mathrm{~m}^{3}$ de lenha pesa cerca de 0,4 tonelada, segundo esse mesmo autor.

Fontes: SOUZA, 1950, p. 264, 271; RECENSEAMENTO, [S.I.: s.n.]; BRASIL, 1898; BRASIL, 1905; BRASIL, 1928; BRASIL, 1950; BRASIL, 1955; BRASIL, 1960.

A Tabela 1 demonstra claramente a maior população do Paraná na região da floresta com araucária em comparação com Santa Catarina e Rio Grande do Sul. Isso se explica por basicamente dois fatores. Em primeiro lugar, o estado tem uma área maior de ocorrência natural da araucária em relação aos outros estados e uma faixa litorânea bastante reduzida, o que encorajou desde cedo a ocupação do planalto. Em segundo lugar, circunstâncias históricas, como a ligação da província com São Paulo e a rota dos 
tropeiros colaboraram para a fixação da capital do estado e importantes núcleos de povoamento e colonização europeia no planalto. ${ }^{4}$

Mapa 1: Área de ocorrência natural da floresta com araucária (Floresta Ombrófila Mista)

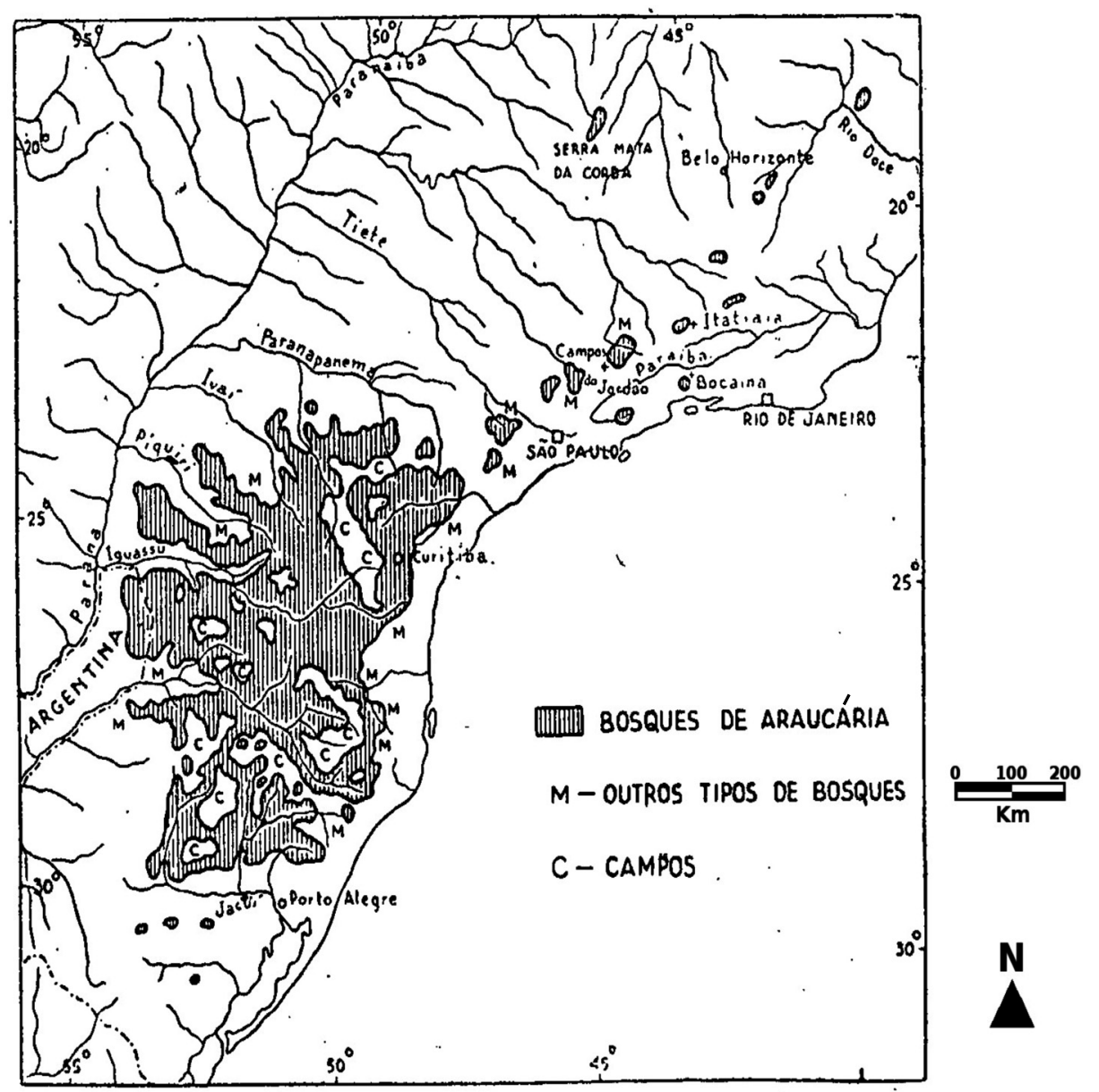

Fonte: HUECK, 1961

${ }^{4}$ A Tabela 1 está delimitada apenas até 1960 em virtude da grande complexidade dos dados para a década de 1970, pois durante a década de 1960 surgiu um grande número de novos municípios, o que colabora para dificultar bastante os cálculos de qual era a população da região da araucária. 
Observando-se a Tabela 1, entende-se também porque a floresta com araucária estava numa situação muito bem conservada em 1872, pois a população humana de acordo com o recenseamento desse ano era de 182 mil habitantes nos municípios da região da araucária, o que significava cerca de 0,7 habitante por $\mathrm{km}^{2} .{ }^{5}$ Se considerarmos, por exemplo, que essa população estava dividida em famílias de 7 pessoas em média, isso significa uma área média de $9,7 \mathrm{~km}^{2}$ ou 970 hectares por família. Claro que isso é uma média, mas não é difícil imaginar que, para os padrões tecnológicos e de consumo do século XIX, essa era uma área de sobra para o sustento dessa hipotética família. Na prática, porém, as famílias não viviam em latifúndios de 970 hectares, mas uma porcentagem significativa das pessoas vivia em pequenas propriedades de 25-30 hectares, relativamente próximas umas das outras, e o avanço sobre as matas nativas se dava em levas (a chamada fronteira agrícola). ${ }^{6} \mathrm{O}$ fim da fronteira agrícola na região da araucária deu-se na década de 1950, com a (re)ocupação do extremo sudoeste do Paraná (Biblioteca Pública do Estado do Paraná, 1950). Nessa época, a população humana da região da araucária era de 2.722 .315 , o que significava 10,7 habitantes por $\mathrm{km}^{2}$, o que representou um adensamento humano 15 vezes maior do que em 1872 . Há de se considerar também que o nível de consumo e a capacidade humana de retirar materiais da natureza (através da tecnologia) se ampliaram consideravelmente nesse período de apenas 80 anos. Como exemplo disso, está a própria evolução tecnológica da indústria madeireira.

Além da Tabela 1, é importante para a discussão do impacto ambiental da população humana sobre a floresta com araucária apresentar um gráfico (Gráfico 2) sobre a evolução da população rural nos três estados do sul do Brasil, uma vez que as cidades, e especialmente as grandes cidades, modificam a relação das populações humanas com os seus recursos naturais.

\footnotetext{
${ }^{5}$ Considerando que a área original do ecossistema era de $253.793 \mathrm{~km}^{2}$, segundo RIBEIRO et al., 2009, p. 1.148.

${ }^{6}$ Essa estimativa de 25-30 hectares não pode ser considerada exata, pois embora esse fosse o tamanho considerado padrão do lote colonial, muitos brasileiros ou caboclos viviam em terrenos não legalmente delimitados que poderiam significar mais ou menos do que esse valor, dependendo até das atividades econômicas desenvolvidas.
} 
Gráfico 2: Evolução histórica da população rural nos três estados do sul do Brasil: porcentagem em relação ao total da população de cada estado (19502000)

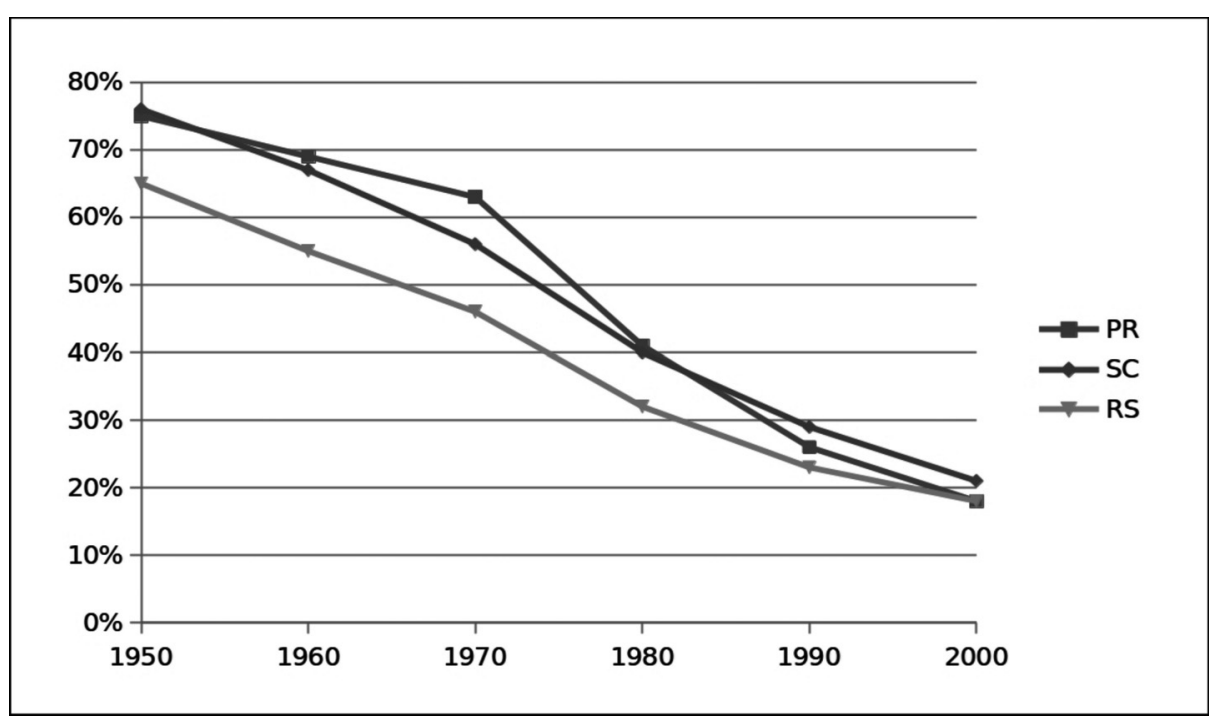

Fonte: BRASIL, 2001, p. 55

O Gráfico 2 inicia em 1950 em virtude do censo populacional discriminar pela primeira vez a população rural da população urbana, até por que era já notável um crescente processo de urbanização da população brasileira como um todo. O que se pode perceber desde 1950 é um declínio constante da população rural em termos relativos à população urbana nos três estados do sul, devido não só ao processo de industrialização do país e das oportunidades de emprego e de busca de maior qualidade de vida nas cidades $^{7}$, mas também à precarização das condições econômicas do campo após 1970 com a modernização agrícola (Revolução Verde), que colaborou para a exclusão econômica da maioria dos agricultores e ao mesmo tempo aumentou a produtividade e diminuiu a necessidade de mão de obra para atender a demanda por alimentos (ALMEIDA; PETERSEN; CORDEIRO, 2001).

\footnotetext{
${ }^{7}$ Desnecessário é lembrar que a busca por uma vida melhor nas cidades nem sempre foi alcançada, ficando muitas vezes no plano das expectativas.
} 
Como se pode observar ainda no Gráfico 2, a população rural era maior do que a população urbana no Paraná e em Santa Catarina até a década de 1970, e no Rio Grande do Sul até a década de 1960. Considerando ainda que o transporte de mercadorias era caro e precário em muitas regiões, pela ausência de estradas asfaltadas em quase todas as localidades até as décadas de 1960 e 1970, e pela existência de poucas ferrovias, é razoável supor que a maior parte do alimento consumido pela população humana da região da araucária era produzido localmente até pelo menos a década de 1960. Caso isso seja verdadeiro, é possível estabelecer uma forte correlação no período anterior a 1960 entre o aumento da população humana e o aumento da área cultivada para alimentar mais pessoas. Para uma análise das décadas mais recentes, essa correlação não seria mais possível, pois com o desenvolvimento e o barateamento dos transportes, a população (principalmente a urbana) consome cada vez mais alimentos produzidos a centenas ou milhares de quilômetros de distância. Assim, um habitante que vive hoje na área do ecossistema da floresta com araucária pode muito bem consumir quase todos os alimentos produzidos em regiões exteriores à área original do ecossistema. ${ }^{8}$

Além do mais, a quase completa ausência de adubação nas lavouras antes da década de 1960 significava que o pousio era necessário para evitar grandes perdas na produtividade. ${ }^{9}$ A prática do pousio significava que uma área significativamente maior de terra precisava ser utilizada (em detrimento das florestas) para produzir a mesma quantidade de alimentos que as técnicas agrícolas introduzidas pela Revolução Verde nas décadas de 1960 e 1970 deram condições de produzir em uma área muito menor. No entanto, não podemos nos esquecer de que as próprias técnicas e métodos da Revolução Verde também causaram sérios problemas ambientais e sociais, como a eutrofização de fontes, rios e lagos devido aos adubos químicos, a contaminação do meio ambiente e de milhares de agricultores por agrotóxicos, além da erosão e compactação do solo pelo uso de tratores (CARVA-

\footnotetext{
${ }^{8}$ Para uma discussão sobre as implicações ecológicas da comida produzida localmente, entre outras questões, ver SINGER e MASON, 2007. Michael Pollan é um autor que ficou famoso com a defesa da comida produzida localmente, porém acaba defendendo o "local" sem uma profundidade crítica em alguns aspectos, como os direitos dos animais (POLLAN, 2007). Para uma crítica a Pollan, ver SINGER; MASON, 2007 e STANESCU, 2010.

${ }^{9}$ Sobre o uso bastante disseminado do pousio no sul do Brasil no século XX anteriormente à Revolução Verde, ver WAIBEL, 1949.
} 
LHO; NODARI; NODARI, 2017). É preciso lembrar também que as técnicas e os métodos desenvolvidos pela agricultura orgânica/agroecológica não têm recebido o mesmo volume de investimentos financeiros públicos e privados para que possam demonstrar todo o seu potencial.

Além da questão dos alimentos produzidos e consumidos localmente e da prática do pousio, é possível estabelecer outra correlação significativa entre o aumento da população da região da araucária e a expansão do desmatamento: o consumo de lenha. Anteriormente à década de 1970, com a disseminação do uso do gás de cozinha, a lenha era o combustível básico das cozinhas e também para o aquecimento nos gélidos invernos do planalto. Considerando ainda que até essa época a maior parte da população vivia no campo, como mostra o Gráfico 2, não é difícil imaginar que a lenha era coletada localmente e raramente deveria ser trazida de regiões distantes, como é comum ainda nos dias de hoje na zona rural (CARVALHO, 2011).

Por outro lado, a expansão da indústria madeireira na região da araucária, embora também influenciada pelo aumento populacional dessa mesma região, vai bem além desse limite. $\mathrm{O}$ aumento da população da região da araucária significou que mais casas, mais igrejas, mais pontes, enfim, mais infraestrutura feita de madeira (ou de tijolos cozidos com lenha) retirada da floresta com araucária era necessária. No entanto, o uso da madeira da araucária, principalmente após a entrada da Companhia Lumber na década de 1910, deixou de ser apenas um uso local e passou cada vez mais ao longo do século XX a abastecer regiões distantes e alheias ao ecossistema, como as cidades de São Paulo, Rio de Janeiro, Buenos Aires e Montevidéu. A madeira da araucária passou a ser uma commodity destinada a abastecer as necessidades de madeira de cidades em rápido crescimento populacional (e crescimento per capita também) localizadas dentro ou a centenas ou milhares de quilômetros fora do ecossistema.

Assim, o que diferencia a exploração madeireira de outras formas de destruição da floresta realizadas até então é que, pela primeira vez, a floresta estava sendo destruída em larga escala para atender demandas externas ao ecossistema, externas aos habitantes do planalto. Anteriormente à exploração madeireira da araucária, a expansão da pecuária nos campos nativos e a extração da erva-mate também tiveram algum impacto sobre a mata, embora em escala muito menor. 


\section{Considerações finais}

Essas correlações estabelecidas entre o aumento da população local e o desmatamento merecem estudos mais detalhados para se conhecer o seu real alcance. A intenção foi apenas apontar importantes correlações para que se possa ter uma compreensão mais clara de quais foram os fatores responsáveis pelo processo histórico de desmatamento das florestas com araucária.

\section{Apêndice \\ População da região da araucária no Paraná, em Santa Catarina e no Rio Grande do Sul (1872-1960)}

A metodologia utilizada consistiu na inclusão dos municípios localizados na área original da floresta com araucária (ver Mapa 1). Em alguns casos houve a exclusão de alguns municípios devido às várias mudanças e aos desmembramentos que ocorreram e também para compensar a inclusão de outros municípios que estão apenas parcialmente inseridos na região da araucária. Para decidir quais municípios estavam na área do ecossistema, foram utilizados mapas da vegetação e informações sobre latitude, altitude e história política dos municípios recolhidos na internet. Em alguns casos, a população dos municípios é colocada entre parênteses para mostrar nesses casos específicos o quanto a inclusão de determinados municípios interfere no total. Como se pode notar, calcular a população da região da araucária está, portanto, sujeito a imprecisões, embora estas não afetem significativamente os resultados para os nossos propósitos. O período analisado é de 1872 a 1960, 1872 por ser a data do primeiro recenseamento e 1960 por ser um período ainda com menos municípios, pois a partir de 1970 apareceu um grande número de novos municípios, o que tornaria muito mais difícil a tarefa já trabalhosa de calcular a população da região da araucária.

\section{Paraná}

1872

População total do estado: 126.722

População da região da araucária: 100.047

Municípios incluídos: Curitiba, São José dos Pinhaes, Votuverava (posteriormente Rio Branco do Sul), Arraial Queimado (posteriormente Bocaiuva do Sul), Campo Largo, Príncipe (Lapa), Rio Negro, Palmeira, Castro, Ponta Grossa, Guarapuava. 


\section{Paraná}

1890

População total do estado: 249.491

População da região da araucária: 207.529

Municípios incluídos: Araucaria, Assunguy de Cima, Bocayuva, Campo Largo, Castro, Colombo, Conchas, Curitiba, Deodoro (Piraquara), Entre Rios (Guaragi, distrito de Ponta Grossa), Glycerio (Campina Grande do Sul), Guarapuava, Imbituva, Jaguaryahiva, Lapa, Palmas, Palmeira, Pirahy, Ponta Grossa, Rio Negro, São João do Triumpho, São José da Boa Vista, São José dos Pinhaes, Tamandaré, Thomazina, Tibagy, União da Victoria, Votuverava (posteriormente Rio Branco do Sul).

\section{Paraná}

1900

População total do estado: 327.136

População da região da araucária: 278.226

Municípios incluídos: Araucaria, Assunguy de Cima, Bella Vista de Palmas (Clevelândia), Bocayuva, Campina Grande, Campo Largo, Castro, Colombo, Conchas, Curityba, Deodoro, Entre Rios, Guarapuava, Imbituva, Jaguaryahiva, Lapa, Palma, Palmeira, Pirahy, Ponta Grossa, Rio Negro, São João de Capanema (Prudentópolis), São João do Triumpho, São José da Boa Vista, São José dos Pinhaes, Tamandaré, Thomazina, Tibagy, União da Victoria, Votuverava, Ypiranga.

\section{Paraná}

1920

População total do estado: 685.711

População da região da araucária: 567.731

Municípios incluídos: Araucaria, Assunguy de Cima, Bocayuva, Campina Grande, Campo Largo, Castro, Clevelandia, Colombo, Conchas, Curityba, Deodoro, Entre Rios, Guarapuava, Iraty, Jaguariahyva, Lapa, Palmas, Palmeira, Palmyra, Pirahy, Ponta Grossa, Prudentopolis, Rio Branco, Rio Negro, Santo Antonio do Imbituva, São João do Triumpho, São José da Boa Vista, São José dos Pinhaes, São Matheus, São Pedro do Mallet, Tamandaré, Teixeira Soares, Thomazina, Tibagy, União da Victoria, Ypiranga.

\section{Paraná}

1940

População total do estado: 1.236 .276

População da região da araucária: 871.762

Municípios incluídos: Araucária, Bocaiuva, Campo Largo, Castro, Cerro Azul, Clevelandia, Curitiba, Guarapuava, Imbituva, Ipiranga, Irati, Jaguariaíva, Lapa, 
Malé, Palmas, Palmeira, Piraí, Piraquara, Ponta Grossa, Prudentópolis, Rebouças, Reserva, Rio Azul, Rio Negro, São João do Triunfo, São José dos Pinhaes, São Mateus, Sengés, Teixeira Soares, Tibagi, Tomazina, União da Vitória, Venceslau Braz.

\section{Paraná}

1950

População total do estado: 2.115 .547

População urbana: $528.288(25 \%)$

População rural: $1.587 .259(75 \%)$

População da região da araucária: 1.156 .087

Municípios incluídos: Araucária, Bocaiúva do Sul, Campo Largo, Campo Mourão, Castro, Cerro Azul, Clevelândia, Colombo, Curitiba, Curiúva, Guarapuava, Ibaiti, Imbituva, Ipiranga, Irati, Jaguariaíva, Lapa, Laranjeiras do Sul, Mangueirinha, Mallet, Palmas, Palmeira, Piraí do Sul, Piraquara, Pitanga, Ponta Grossa, Porto Amazonas, Prudentópolis, Rebouças, Reserva, Rio Azul, Rio Branco do Sul, Rio Negro, São João do Triunfo, São José dos Pinhais, São Mateus do Sul, Sengés, Teixeira Soares, Tibagi, Timoneira (Almirante Tamandaré), Tomazina, União da Vitória e Wenceslau Braz.

\section{Paraná}

1960

População total do estado: 4.268 .239

População urbana: $1.310 .969(30 \%)$

População rural: $2.952 .752(70 \%)$

População da região da araucária: 1.966 .097

Municípios incluídos: Almirante Tamandaré, Arapoti, Araruna, Araruva (posteriormente Marilândia do Sul), Araucária, Barracão, Bituruna, Bocaiúva do Sul, Campina Grande do Sul, Campo Largo, Campo Mourão, Candido de Abreu, Cascavel, Castro, Cerro Azul, Chopinzinho, Clevelândia, Colombo, Contenda, Coronel Vivida, Cruz Machado, Curitiba, Curiúva, Faxinal, Francisco Beltrão, Guaraniaçu, Guarapuava, Ibaiti, Imbituva, Ipiranga, Irati, Jaguariaíva, Japira, Lapa, Laranjeiras do Sul, Mallet, Mangueirinha, Manuel Ribas, Ortigueira, Palmas, Palmeira, Pato Branco, Paulo Frontin, Pinhalão, Piraí do Sul, Piraquara, Pitanga, Ponta Grossa, Porto Amazonas, Prudentópolis, Rebouças, Reserva, Rio Azul, Rio Branco do Sul, Rio Negro, Santo Antonio (posteriormente Santo Antonio do Sudoeste), São João do Triunfo, São José dos Pinhais, São Mateus do Sul, Sengés, Teixeira Soares, Tibagi, Tijucas do Sul, Toledo, Tomazina, União da Vitória, Wenceslau Braz. 


\section{Santa Catarina}

1872

População total do estado: 159.802

População da região da araucária: 12.785

Municípios incluídos: Lages e Conceição dos Coritibanos.

\section{Santa Catarina}

1890

População total do estado: 283.769

População da região da araucária: 38.738

Municípios incluídos: Coritibanos, Lages, São Bento, São João de Campos Novos, São Joaquim da Costa da Serra.

\section{Santa Catarina}

1900

População total do estado: 320.289

População da região da araucária: 46.958

Municípios incluídos: Campo Alegre, Campos Novos, Costa da Serra, Curytibanos, Lages, São Bento.

\section{Santa Catarina}

1920

População total do estado: 636.605

População da região da araucária: 167.135

Municípios incluídos: Campo Alegre, Campos Novos, Canoinhas, Chapecó (11.315), Cruzeiro (13.335), Curitybanos, Itayopolis, Lages, Mafra, Porto União, São Bento, São Joaquim.

\section{Santa Catarina}

\section{0}

População total do estado: 1.178 .340

População da região da araucária: 431.387

Municípios incluídos: Bom Retiro, Caçador, Campo Alegre, Campos Novos, Canoinhas, Chapecó (44.327), Concordia (32.658), Cruzeiro (36.174), Curitibanos, Itaiopolis, Lajes, Mafra, Porto União, São Bento, São Joaquim.

\section{Santa Catarina}

\section{0}

População total do estado: 1.560 .502

População urbana: 305.445 (19\%) 
População rural: 966.214 (81\%)

População da região da araucária: 518.419

Municípios incluídos: Bom Retiro, Caçador, Campo Alegre, Campos Novos, Canoinhas, Chapecó (96.626), Joaçaba (48.299), Curitibanos, Itaiopolis, Lajes, Mafra, Porto União, São Bento do Sul, São Joaquim, Videira (23.625).

\section{Santa Catarina}

1960

População total do estado: 2.129 .252

População urbana: 688.358 (32\%)

População rural: 1.440 .894 (68\%)

População da região da araucária: 703.480

Municípios incluídos: Água Doce, Bom Retiro, Caçador, Campo Alegre, Campos Novos, Canoinhas, Chapecó (52.089), Joaçaba (34.088), Curitibanos, Herval do Oeste, Itaiopolis, Lajes, Mafra, Papanduva, Ponte Serrada, Porto União, Rio das Antas, Rio Negrinho, São Bento do Sul, São Joaquim, Tangará, Videira.

\section{Rio Grande do Sul}

1872

População total do estado: 434.813

População da região da araucária: 69.312

Municípios incluídos: Cruz Alta (30.662), Passo Fundo, Santo Antonio da Patrulha (Desse último município apenas as freguesias de S. Francisco de P. de Cima da Serra, N. S. de Oliveira da Vaccaria, S. Paulo da Lagoa Vermelha)

\section{Rio Grande do Sul}

1890

População total do estado: 897.455

População da região da araucária: 169.838

Municípios incluídos: Bento Gonçalves, Caxias, Cruz Alta (16.440), Lagoa Vermelha, Passo Fundo, Santo Antonio da Palmeira, São Francisco de Paula de Cima da Serra, São Martinho (14.925), Soledade, Vacaria.

\section{Rio Grande do Sul}

1900

População total do estado: 1.149 .070

População da região da araucária: 220.586

Municípios incluídos: Alfredo Chaves (posteriormente Veranópolis), Antonio Prado, Bento Gonçalves, Caxias, Cruz Alta (23.671), Garibaldi, Lagoa Vermelha, Palmeira, Passo Fundo, São Martinho (12.885), Soledade, Vacaria, Villa Rica (8.163). 


\section{Rio Grande do Sul}

1920

População total do estado: 2.182 .713

População da região da araucária: 521.661

Municípios incluídos: Alfredo Chaves, Antonio Prado, Bento Gonçalves, Bom Jesus, Caxias, Cruz Alta (42.046), Erechim, Garibaldi, Guaporé, Julio de Castilhos, Lagoa Vermelha, Palmeira, Passo Fundo, São Francisco de Paula, Soledade, Vacaria.

\section{Rio Grande do Sul}

\section{0}

População total do estado: 3.320 .689

População da região da araucária: 871.389

Municípios incluídos: Alfredo Chaves, Antonio Prado, Bento Gonçalves, Carazinho, Caxias, Cruz Alta (57.515), Farroupilha, Flores da Cunha, Garibaldi, Getulio Vargas, Guaporé, José Bonifacio (Erechim), Julio de Castilhos (21.269), Lagoa Vermelha, Palmeira, Passo Fundo, Prata, São Francisco de Paula, Sarandi, Soledade, Vacaria.

\section{Rio Grande do Sul}

\section{0}

População total do estado: 4.164 .821

População rural: $2.742 .841(65 \%)$

População urbana: 1.421 .980 (35\%)

População da região da araucária: 1.047.809.

Municípios incluídos: Antonio Prado, Aparados da Serra, Bento Gonçalves, Carazinho, Caxias do Sul, Cruz Alta (64.721), Erechim, Farroupilha, Flores da Cunha, Garibaldi, Getulio Vargas, Guaporé, Julio de Castilhos (24.618), Lagoa Vermelha, Nova Prata, Palmeira das Missões, Passo Fundo, São Francisco de Paula, Sarandi, Soledade, Vacaria, Veranópolis.

\section{Rio Grande do Sul}

\section{0}

População total do estado: 5.366 .720

População rural: 2.985 .937 (55\%)

População urbana: 2.380 .783 (45\%)

População da região da araucária: 1.255.627.

Municípios incluídos: Antonio Prado, Arvorezinha, Bento Gonçalves, Bom Jesus, Campinas do Sul, Canela, Carazinho, Carlos Barbosa, Casca, Caxias do Sul, Chapada, Constantina, Cruz Alta, Erechim, Farroupilha, Flores da Cunha, Garibaldi, 
Gaurama, Getulio Vargas, Gramado, Guaporé, Ibirubá, Julio de Castilhos, Lagoa Vermelha, Machadinho, Marau, Não me toque, Nova Petrópolis, Nova Prata, Palmeira das Missões, Passo Fundo, Sananduva, Santa Barbara do Sul, Santo Augusto, São Francisco de Paula, São José do Ouro, São Valentim, Sarandi, Seberi, Soledade, Tapejara, Vacaria, Veranópolis, Viadutos.

Fonte do apêndice: RECENSEAMENTO, [S.I.: s.n.]; BRASIL,1898; BRASIL, 1905; BRASIL, 1928; BRASIL, 1950; BRASIL, 1955; BRASIL, 1960.

\section{Referências}

ALMEIDA, Sílvio Gomes de; PETERSEN, Paulo; CORDEIRO, Angela. Crise socioambiental e conversão ecológica da agricultura brasileira: subsídios à formulação de diretrizes ambientais para o desenvolvimento agrícola. Rio de Janeiro: AS-PTA, 2001.

BRANNSTROM, Christian. A madeira foi o combustível que moveu a industrialização brasileira? In: FRANCO, José Luiz de A.; DUTRA e SILVA, Sandro; DRUMMOND, José Augusto; TAVARES, Giovana Galvão. História Ambiental: fronteiras, recursos naturais e conservação da natureza. Rio de Janeiro: Garamond, 2012, p. 39-75.

CARVALHO, Miguel Mundstock Xavier de. Os fatores do desmatamento da Floresta com Araucária: agropecuária, lenha e indústria madeireira. Esboços, Florianópolis, v. 18, n. 25, p. 32-52, ago., 2011.

CARVALHO, Miguel Mundstock Xavier de; NODARI, Eunice Sueli; NODARI, Rubens Onofre. "Defensivos" ou "agrotóxicos"? História do uso e da percepção dos agrotóxicos no estado de Santa Catarina, Brasil, 1950-2002. História, Ciências, Saúde-Manguinhos, Rio de Janeiro, v. 24, n. 1, p. 75-91, jan./mar. 2017.

HUECK, Kurt. Transcrição - Distribuição e habitat natural do Pinheiro-do-Paraná (Araucaria angustifolia): contribuições para a pesquisa fitossociológica paulista. Boletim Geográfico, IBGE, n. 165, p. 709-723, nov./dez., 1961.

McNEILL, John R. Population and the Natural Environment: Trends and Challenges. Population and Development Review. The Political Economy of Global Population Change: 1950-2050, v. 32, 2006.

POLLAN, Michael. O dilema do onivoro: uma história natural de quatro refeições. Rio de Janeiro: Intrínseca, 2007.

RIBEIRO, Milton Cezar et al. The Brazilian Atlantic Forest: How much is left, and how is the remaining forest distributed? Implications for conservation. Biological Conservation, n. 142, p. 1.148, 2009. 
SINGER, Peter; MASON, Jim. A ética da alimentação: como nossos hábitos alimentares influenciam o meio ambiente e o nosso bem-estar. Rio de Janeiro: Elsevier, 2007.

SOUZA, Aníbal P. de. A lenha como base do progresso industrial. Anuário Brasileiro de Economia Florestal, Rio de Janeiro; Instituto Nacional do Pinho, ano 3, n. 3, 1950.

STANESCU, Vasile. "Green" Eggs and Ham? The Myth of Sustainable Meat and the Danger of the Local. Journal for Critical Animal Studies, v. 8, n. 1/2, 2010.

WAIBEL, Leo. Princípios da Colonização Europeia no Sul do Brasil. Revista Brasileira de Geografia, ano XI, n. 2, p. 159-217, 1949.

WILLIAMS, Michael. Deforesting the Earth: from prehistory to global crisis: an abridgment. Chicago: The University of Chicago Press, 2006.

\section{Fontes primárias}

BIBLIOTECA Pública do Estado do Paraná. Mapa fitogeográfico do Estado do Paraná. Organizado e desenhado pelo Serviço de Geologia e Petrografia do Instituto de Biologia e Pesquisas Tecnológicas da Secretaria de Agricultura, Indústria e Comércio em colaboração com o Instituto Nacional do Pinho. Levantamentos, dados, pesquisas e construção de Reinhard Maack. 1950.

BRASIL. Ministério da Indústria, Viação e Obras Públicas. Directoria Geral de Estatística. Synopse do recenseamento de 31 de dezembro de 1890. Rio de Janeiro: Officina da Estatística, 1898. Disponível em: <http://biblioteca.ibge.gov.br/>. Acesso em: 05 maio 2017.

BRASIL. Ministério da Indústria, Viação e Obras Públicas. Directoria Geral de Estatística. Synopse do recenseamento de 31 de dezembro de 1900. Rio de Janeiro: Typographia da Estatística, 1905. Disponível em: <http://biblioteca.ibge.gov.br/>. Acesso em: 05 maio 2017.

BRASIL. Ministério da Agricultura, Indústria e Commercio. Recenseamento do Brazil: realizado em 1 de Setembro de 1920. V. 4 (2 $2^{\text {a }}$ parte). Tomo II. Rio de Janeiro: Typographia da Estatística, 1928. Disponível em: <http://biblioteca.ibge.gov.br/>. Acesso em: 05 maio 2017.

BRASIL. Instituto Brasileiro de Geografia e Estatística. Recenseamento Geral do Brasil: 1 de Setembro de 1940. Censo Demográfico. Rio de Janeiro: Serviço Gráfico do Instituto Brasileiro de Geografia e Estatística, 1950. Disponível em: <http:// biblioteca.ibge.gov.br/>. Acesso em: 05 maio 2017.

BRASIL. Instituto Brasileiro de Geografia e Estatística. VI Recenseamento Geral do Brasil: 1950. Censo Demográfico. Rio de Janeiro: 1955. Disponível em: <http:// biblioteca.ibge.gov.br/> . Acesso em: 05 maio 2017. 
BRASIL. Fundação Instituto Brasileiro de Geografia e Estatística. Censo Demográfico de 1960: VII Recenseamento Geral do Brasil. Disponível em: <http:// biblioteca.ibge.gov.br/>. Acesso em: 05 maio 2017.

BRASIL. Ministério do Planejamento e Coordenação Geral. Fundação IBGE Instituto Brasileiro de Geografia e Estatística. Departamento de Censos. Censo Demográfico de 1970. VIII Recenseamento Geral. Disponível em: <http:// biblioteca.ibge.gov.br/>. Acesso em: 05 maio 2017.

BRASIL. Ministério de Planejamento, Orçamento e Gestão. Instituto Brasileiro de Geografia e Estatística. Sinopse preliminar do Censo Demográfico 2000. V. 7. Rio de Janeiro: IBGE, 2001, p. 55. Disponível em: <http://biblioteca.ibge.gov.br/>. Acesso em: 05 maio 2017.

RECENSEAMENTO do Brazil 1872. [S.I.: s.n.]. Disponível em: <http:// biblioteca.ibge.gov.br/>. Acesso em: 05 maio 2017. 